\title{
Reliability Analysis of SiC MOSFET Power Module for More Electric Aircraft Motor Drive Applications
}

\author{
Shane O'Donnell \\ Department of Electrical and \\ Electronic Engineering \\ University of Nottingham \\ Nottingham, UK \\ shane.odonnell@nottingham.ac.uk
}

\author{
Prof. Pat Wheeler \\ Department of Electrical and \\ Electronic Engineering \\ University of Nottingham \\ Nottingham, UK \\ pat.wheeler@nottingham.ac.uk
}

\author{
Dr. Alberto Castellazzi \\ Department of Electrical and \\ Electronic Engineering \\ University of Nottingham \\ Nottingham, UK \\ alberto.castellazzi@nottingham.ac.uk
}

\begin{abstract}
This paper presents a reliability study on a Microsemi 5 kVA Integrated Power Solutions (IPS) module designed to drive an electrical motor in a More Electric Aircraft actuation system. The measures taken in the design of the product and the reliability advantages of incorporating siliconcarbide MOSFETs as an alternative to silicon IGBTs are detailed. The MTBF of the unit is presented and a laboratory test setup for verifying the results is outlined.
\end{abstract}

Keywords-Reliability, Silicon Carbide MOSFETs, More Electric Aircraft, FIDES, mission model, integrated power solutions

\section{INTRODUCTION}

When designing a power module for critical applications, such as commercial aviation primary flight controls, adequate design measures and extensive analysis are essential to ensure reliable operation. When this power module is placed in a non-pressurised area, for example, on the aircraft wing, it may be exposed to extremely harsh environmental conditions.

The design measures adopted by Microsemi in the design of its $5 \mathrm{kVA}$ "Power Core Module" (PCM) [1] to ensure reliable operation is presented in this paper. High grade components, optimised for electrical and thermal performance, were selected and the interconnects between sub-systems are designed and placed to increase heat transfer and maintain stable operating temperatures. Using a mission profile for a single-aisle aircraft, analysis of power dissipation and thermal performance highly influenced the selection and placement of components. Reliability calculations, based on the FIDES reliability methodology for electronic systems [2], were performed and a method of verifying the results is presented.

In modern aircraft, the use of Insulated Gate Bipolar Transistor (IGBT) technology is currently the favoured approach in the design of power converters used for driving electrical motors. These devices meet the fundamental requirements for the application and as they have been widely used for many years, their characteristics are well known and their reliability is very much established. However, wide bandgap semiconductor materials, such as silicon carbide (SiC), have properties which offer significant advantages over silicon (Si) in More Electric Aircraft (MEA) [3], [4]. These include improved power density, resulting in reduced size and weight; lower losses, resulting in reduced heat-sinking; and operation at higher junction temperatures, which again positively impacts heat-sink requirements and also facilitates operation in high temperature environments, such as near the engine, [5], [6], [7], [8], [9]. The use of SiC MOSFETs in aerospace, however, has been somewhat limited due to their relative immaturity and lack of heritage in critical applications. Power modules designed for such applications are expected to last for up to 150,000 flight hours of operation and therefore the life-time of individual components must far exceed this requirement.

This paper presents the mean time between failure (MTBF) figure for the PCM using the FIDES method, where the mission profile, and therefore the flight hours, is incorporated in the calculation. Also, a laboratory setup for verifying this reliability figure is described.

\section{Power Core Module Design}

The PCM comprises of three sub-systems, a substrate assembly with a heatsink base, a driver printed circuit board (PCB) assembly and a telemetry PCB assembly. The compact module, with dimensions of $105 \mathrm{~mm} \times 85 \mathrm{~mm} \times 30 \mathrm{~mm}$ and weight of $<300 \mathrm{~g}$ is shown in Fig. 1.

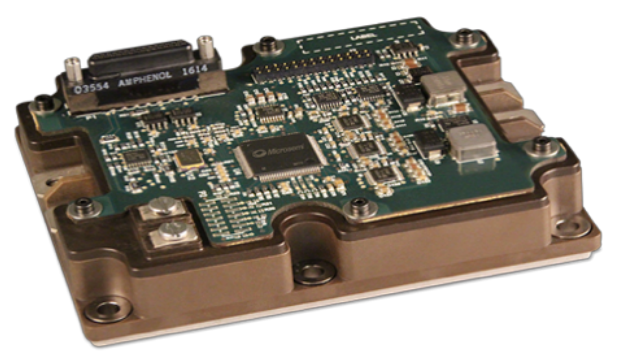

Fig. 1: Microsemi’s 5 kVA Power Core Module

The PCM baseplate material is $\mathrm{AlSiC}$ and together with a $\mathrm{Si}_{3} \mathrm{~N}_{4}$ substrate, offers improved reliability, thermal performance and reduced weight over other material combinations used in commercial or industrial applications. During the design phase, stress analysis was performed on the substrate and PCB assemblies to assess the performance of these sub-assemblies over a temperature range of $-55^{\circ} \mathrm{C}$ to $+110{ }^{\circ} \mathrm{C}$ and for output currents of $12.5 \mathrm{~A}$ and $25 \mathrm{~A}$. The resulting voltage stress levels on the capacitors were less than $40 \%$ and the power stress levels on the resistors did not exceed $20 \%$. Furthermore, the stress levels on the telemetry board PCB assembly were minimal.

In addition to the electrical and power connections between the driver PCB assembly and the substrate assembly, thermal pins are strategically placed to dissipate heat from the 
driver PCB to the baseplate, which acts as a heat sink. This measure ensures all components remain comfortably within their operating margin. Fig. 2 displays the substrate assembly with the exploded view displaying some of the pins used for thermal dissipation and for connecting signals and power between the driver circuitry and the power semiconductors.

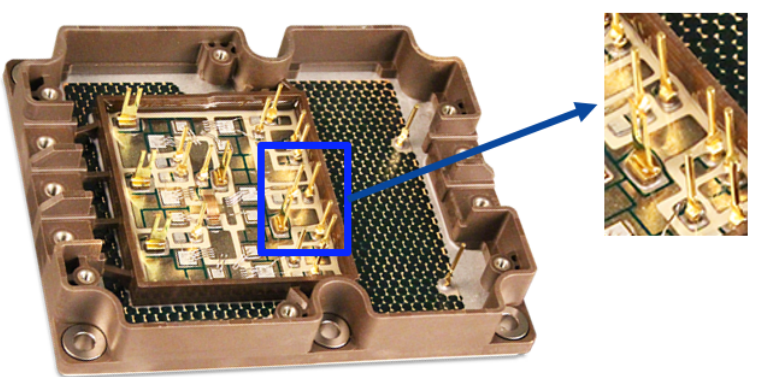

Fig. 2: PCM substrate assembly

Reducing the operating temperature and mechanical stresses on devices is an effective method of increasing product reliability.

\section{MisSION MODELLING}

An aileron actuation system was modelling using the MathWorks' MATLAB and Simulink tools. Fig. 3 [10], displays a high-level view of this model. An input data set, representing actuator position commands from the flight controller, is the input to the model and as shown, torque disturbances were also considered.

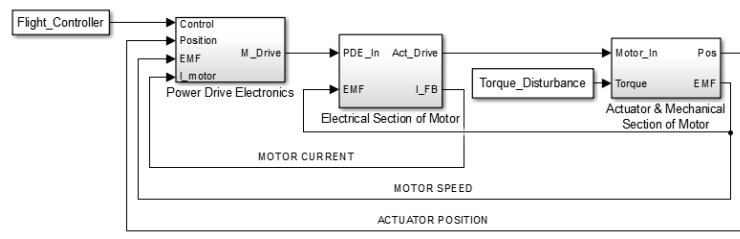

Fig. 3: Model of aileron actuation system

The model contains three loops controlling the motor current, motor speed and actuator position. The motor speed loop controls the stabilisation of the actuator and includes factors representing torque and inertia. The motor speed and actuator position loops were simulated to derive the output current requirements for the application.

The input data set includes information for the different flight phases which are shown in Fig. 4. As the aileron controls the movement around the longitudinal axis, it is expected that it will be most active during climbing and descending with some activity, primarily to maintain stability, during the cruising phase.

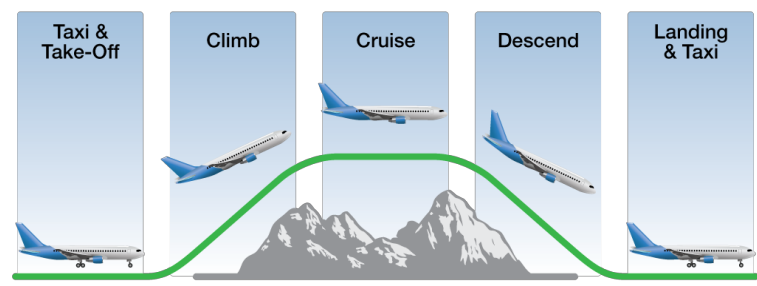

Fig. 4: Aircraft Mission Profile
The Iq values, which represent the equivalent output current from the motor to the actuator for the defined flight phases are plotted in Fig. 5.

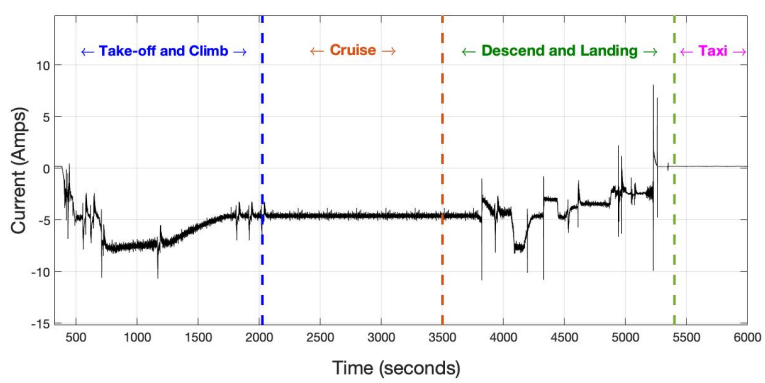

Fig. 5: Output current for various flight phases

The polarity of the current represents the sign of the hinge moment with the value representing the aerodynamic effort during the flight. As expected, the most extreme output currents are seen during the take-off, climbing, descending and landing phases of the mission.

The power dissipation calculations for each component, based on these output currents were then completed followed by a thermal analysis of the components and sub-systems in an appropriately sized enclosure with two cooling surfaces. The maximum operating temperature increases of the components, which are inputs to the FIDES reliability model, were calculated.

A review of the steady-state solution shows that even the moderate increase in power dissipation levels for the IGBT configuration result in skin temperatures approximately $40{ }^{\circ} \mathrm{C}$ higher than those for a $\mathrm{SiC} 3$-phase bridge. Fig. 6 displays how the time dependent power dissipations and the constant power levels compare for the two semiconductor solutions over a typical flight.
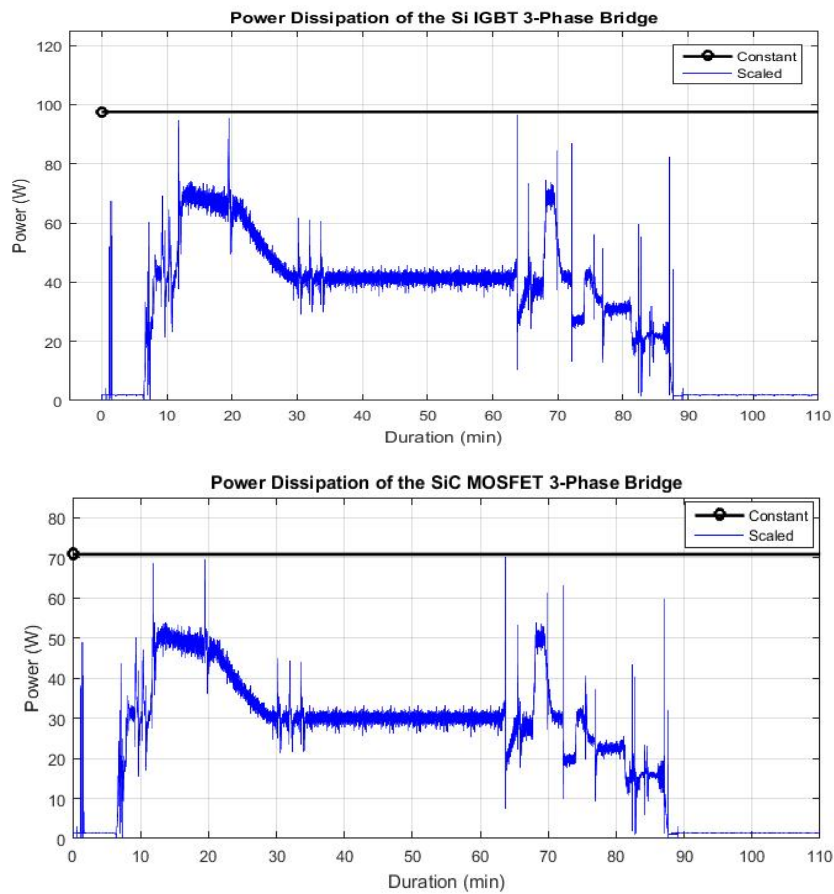

Fig. 6: Comparison of power dissipations of SiC MOSFETs and IGBTs 
As displayed in Fig. 6, using SiC MOSFETs results in a reduction of approx. $30 \%$ in peak and scaled power dissipations figures over the mission profile. This has a positive impact on thermal characteristics and heat-sinking and is advantageous when determining system reliability.

\section{FIDES RELIABILITY METHOdOlOGY FOR ElECTRONIC SYSTEMS}

The FIDES method of reliability calculation was used to calculate the MTBF of the PCM.

The FIDES Group was created in 2000 by the French DGA (Ministry of Defence) and its founders: MBDA, Thales Avionics, Thales Underwater Systems, Thales Airborne Systems, Thales Security Solutions and Services, Nexter Electronics and Eurocopter. The first release of the mythology was in 2004 and the FIDES Guide 2009, used in this analysis, was released in 2010. Documentation and calculation tools can be downloaded from the FIDES website (www.fides-reliability.org).

Per the FIDES Guide [2], this global electronic reliability engineering methodology guide is composed of two parts:

- a predicted reliability evaluation guide and

- a reliability process control and audit guide

and the objectives of the guide are

- to make a realistic evaluation of the reliability of electronic products, including systems that encounter severe or nonaggressive environments and

- $\quad$ to provide a specific tool for the construction and control of this reliability.

Its main characteristics are:

- The existence of models for electrical, electronic and electromagnetic components, and for electronic boards or some sub-assemblies.

- Demonstration and taking account of all technological and physical factors that have an identified role in reliability.

- $\quad$ Precisely taking account of the life profile.

- Taking account of electrical, mechanical and thermal overstresses.

- Taking account of failures related to the development, production, operation and maintenance processes.

- The possibility of making a distinction between several suppliers of a single component.

The FIDES Guide can be helpful for taking action on definitions and throughout the product life cycle to control and improve reliability, through the identification of technological, physical and process factors contributing to the reliability.

The reasons why the FIDES methodology was used in this study were:

- The strong aviation heritage among its founding members.

- The strong emphasis towards aviation in the method.
- The inclusion of technology and process factors in the calculations.

- The ability to incorporate the mission profile and phases into the calculations.

- The ability of the method to present the effects of various factors, such as thermal cycling and humidity in the overall reliability.

- The method is accepted by major companies in the aviation industry.

\section{Mission DEPENDENT RELIABILITy ANALysis}

To calculate the reliability of the PCM, the information shown in TABLE 1 was incorporated into the FIDES analysis tool to represent the or life profile.

TABLE 1

AIRCRAFT PHASE DETAILS IN FIDES MODEL

\begin{tabular}{|l|l|c|c|c|}
\hline \multirow{2}{*}{$\begin{array}{c}\text { Phase } \\
\text { Name }\end{array}$} & $\begin{array}{c}\text { Equipment } \\
\text { on/off }\end{array}$ & $\begin{array}{c}\text { Calendar } \\
\text { Time } \\
\text { (Hours) }\end{array}$ & $\begin{array}{c}\text { PT }\left({ }^{\circ} \text { C) }\right. \\
\text { during phase }\end{array}$ & $\begin{array}{c}\text { Maximum } \\
\text { Temperature } \\
\text { during } \\
\text { cycling }\end{array}$ \\
\hline $\begin{array}{l}\text { Ground } \\
\text { Operating }\end{array}$ & ON & 2,622 & 15 & $40^{\circ} \mathrm{C}$ \\
\hline Taxiing & ON & 312 & 15 & $40^{\circ} \mathrm{C}$ \\
\hline $\begin{array}{l}\text { Climbing } \\
\text { /Descending }\end{array}$ & ON & 1,240 & 40 & $35^{\circ} \mathrm{C}$ \\
\hline Cruise & ON & 1,240 & 0 & $5{ }^{\circ} \mathrm{C}$ \\
\hline $\begin{array}{l}\text { Ground } \\
\text { Dormant }\end{array}$ & OFF & 3,346 & 15 & $35^{\circ} \mathrm{C}$ \\
\hline
\end{tabular}

This life profile with a calendar time equating to a full calendar year, together with component and assembly details and component temperature rise is inputted into the FIDES ExperTool [11] with various $\Pi$ factors representing variables such as process, manufacturing and environmental details.

This subsequently generates the MTBF and FIT data presented in TABLE 2. Though the non-pressurised results, for the aileron application, are more relevant, the pressurised are also shown for completeness. These would be applicable if the PCM was used in an application inside the aircraft cabin for example. The results are significantly better in the pressurised environment, as the unit is not subjected to severe temperature cycling, humidity or vibration effects.

The contribution by phase and stress for the nonpressurised environment is displayed in Fig. 7. As shown, thermal cycling from the climbing and descending of the aircraft is the main contributory factor to the unit's FIT rate. However, when the unit is placed in a pressurised location, not only is the MTBF significant higher, but being powered up on the ground, prior to take-off, has the most impact on the reliability. This illustrates that the reliability of the unit not only depends on the environment in which it is placed, but also on the mission profile of the aircraft and hence shows the importance of introducing the latter into the calculations. If the unit is placed in a long-haul aircraft, where it is subjected to less take-off and landing phases and more time cruising, it will have an increased MTBF. This analysis aligns with the previous data presented in Fig. 5. 


\begin{tabular}{|l|l|c|c|}
\hline Environment & \multicolumn{1}{|c|}{$\begin{array}{c}\text { Sub- } \\
\text { system }\end{array}$} & FIT & $\begin{array}{c}\text { Sub-system } \\
\text { MTBF }\end{array}$ \\
\hline $\begin{array}{l}\text { Non- } \\
\text { pressurised }\end{array}$ & $\begin{array}{l}\text { Telemetry } \\
\text { board }\end{array}$ & 376.8 & 751,375 \\
\hline & $\begin{array}{l}\text { Driver } \\
\text { board }\end{array}$ & 332.0 & 852,891 \\
\hline & Substrate & 153.1 & $1,849,528$ \\
\hline & TOTAL & 328,509 \\
\hline Pressurised & $\begin{array}{l}\text { Telemetry } \\
\text { board }\end{array}$ & 126.5 & $2,237,617$ \\
\hline & $\begin{array}{l}\text { Driver } \\
\text { board }\end{array}$ & 124.4 & $2,276,479$ \\
\hline & Substrate & 126.5 & $2,614,031$ \\
\hline & TOTAL & & 788,190 \\
\hline
\end{tabular}

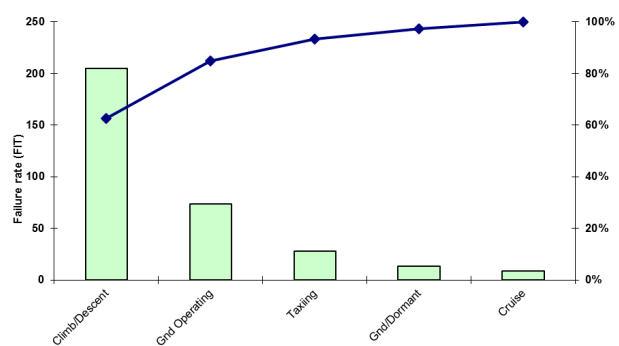

Fig. 7a: Contribution by phase in a non-pressurised environment

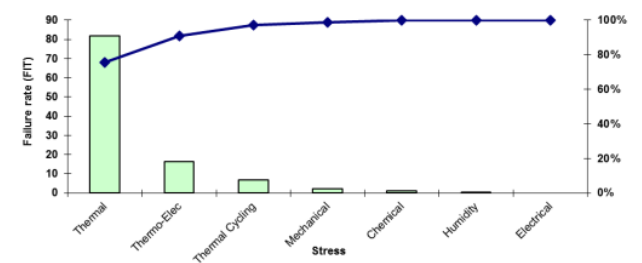

Fig. 7b: Contribution by stress in a non-pressurised environment

\section{VERIFYING THE MTBF}

An accelerated laboratory test has been devised to verify the MTBF results presented in Section V. Accelerated lifetime testing is well-established terminology which refers to accelerating the rate at which physical processes are activated by increasing the operating temperature. The test proposed for the PCM is a combined higher frequency/time dense mission profile. Using a test chamber with pressure and temperature variation, different flight phases are simulated. The pressure varies between a sea-level value of 1 bar and 116 mbar, which represents an altitude of approximately 50,000 feet while the temperature changes from $+40^{\circ} \mathrm{C}$ to $-55^{\circ} \mathrm{C}$. The tests are run over short phase durations rather that those presented in TABLE 1. Two cycles of this profile are shown in Fig. 8.

The quantity of units, cycles and test duration are combined to verify a PCM lifetime greater than 150,000 flight hours. With a typical flight time of 75 minutes, this equates to 120,000 flights. Therefore, as an example, using 25 units and cycling over a 12-minute duration, a total test time of 40 days is required. The duration shown in Fig. 8 for each cycle is dependent on a number of factors such as the temperature ramp rates of the chamber so the precise value can vary depending on the quantity of units and equipment used.

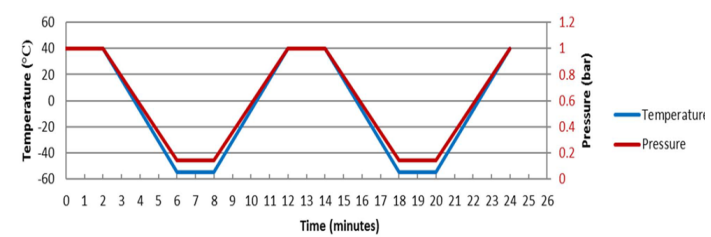

Fig. 8: Accelerated Mission Profile Test

\section{CONCLUSION}

This paper details the importance placed on reliability in the development of the Power Core Module unit designed for More Electric Aircraft motor drive applications. From the early design stages, component selections and sub-system connections ensured power dissipations and resultant heat was reduced using a good thermal path to an effective heatsink. The module contains SiC MOSFETS and while these parts are immature relative to IGBTs in such applications, analysis has shown that a considerable reduction in overall system power dissipation can be achieved with these devices. MTBF figures for the PCM, calculated using the application-specific FIDES methodology are presented and a viable method of verifying the reliability performance of the unit has been outlined.

\section{REFERENCES}

[1] Microsemi Corporation, Power Core Module data sheet, Rev. 1/2017

[2] FIDES Group, FIDES Guide 2009, Edition A

[3] P. W. Wheeler, "The more electric aircraft: Why aerospace needs power electronics?" Power Electronics and Applications, 2009. EPE '09. 13th European Conference on, pp. 1-30

[4] De, D., Castellazzi, A., Lopez-Arevalo, S., Lamantia, A.: SiC MOSFET based avionic power supply, Power Electronics, Machines and Drives (PEMD 2014), 7th IET International Conference on, pp. 16

[5] J. Millan, P. Godignon, X. Perpinya, A. Perez-Tomas and J. Rebollo: A Survey of Wide Band Gap Power Semiconductor Devices, IEEE Transactions on Power Electronics, Vol. 29 no. 5, pp. 2155-2163

[6] J. Biela, M. Schweizer, S. Waffler, B. Wrzecionko, and J. W. Kolar: $\mathrm{SiC}$ versus $\mathrm{Si}-$ Evaluation of potentials for performance improvement of Inverter and DC-DC Converter Systems by SiC Power Semiconductors, IEEE Transactions on Industrial Electronics, Vol. 58 no. 7

[7] A. Elasser and T.P. Chow: Silicon Carbide Benefits and Advantages for Power Electronics Circuits and Systems, Proc. IEEE, Vol. 90, pp. 969-986

[8] Lixing Fu, Xuan Zhang, Scott, M., Chengcheng Yao, Jin Wang: The evaluation and application of wide bandgap power devices, Transportation Electrification Asia-Pacific (ITEC Asia-Pacific), 2014 IEEE Conference and Expo, pp. 1-5

[9] Haihong Qin, Bin Zhao, Xin Nie, Jiaopu Wen, Yangguang Yan: Overview of $\mathrm{SiC}$ power devices and its applications in power electronic converters, 8th IEEE Conference on Industrial Electronics and Applications (ICIEA), pp. 466-471

[10] O’Donnell, Shane, Castellazzi, Alberto, Debauche, Jean-Louis, Wheeler, Pat, Silicon Carbide MOSFETs in More Electric Aircraft Power Converters: The Performance and Reliability benefits over Silicon IGBTs for a specified Flight Mission Profile, 2016 18th European Conference on Power Electronics and Applications, EPE'16 ECCE Europe, art no. 7695504 DOI: 10.1109/EPE.2016.7695504

[11] FIDES, FIDES ExperTool, 2013. [Online]. Available: https://www.fides-reliability.org. [Accessed: 27-Sep-18]. 